Exploring the role of professional associations in collective learning in London and New York's advertising and law professional service firm clusters.

\author{
James Robert Faulconbridge \\ Department of Geography, \\ Lancaster University, \\ Lancaster, \\ LA1 4YW \\ U.K.
}

Email for correspondence: j.faulconbridge@lancaster.ac.uk

Draft: do not cite without author's permission 


\begin{abstract}
The value of regional economies for collective learning has been reported by numerous scholars. However often work has been criticised for lacking analytical clarity and failing to explore the architectures of collective learning and the role of the knowledge produced in making firms in a cluster economy successful. This paper engages with these problematics and investigates how collective learning is facilitated in the advertising and law professional service firm clusters in London and New York. It explores the role of professional associations and investigates how they mediate a collective learning process in each city. It argues that professional associations seed urban communities of practice that emerge outside of the formal activities of professional associations. In these communities individual with shared interests in advertising and law learn from one-another and are therefore able to adapt and evolve one-another approaches to common industry challenges. The paper suggests this is another form of the variation Marshall highlighted in relation to cluster-based collective learning. The paper also shows how the collective learning process is affected by the presence, absence and strength of an institutional thickness. It is therefore argued that a richer understanding of institutional affects is needed in relation to CL.
\end{abstract}




\section{Exploring the role of professional associations in collective learning in London and New York's advertising and law professional service firm clusters.}

\section{1) Introduction}

The 'knowledge economy' has aroused great interest in recent years with the hallmark of the successful firm being innovation based upon knowledge of markets and production technologies (Hodgson, 1999; Skymre, 1999). In tandem it has been suggested that 'learning regions' (Florida, 1995), innovative milieus (Camagni, 1991) and clusters (Porter, 1998) are important spatial formations that, amongst other things, encourage a process of collective learning $(\mathrm{CL})$ that creates 'hot-spots' of innovation such as Silicon Valley (Malmberg and Maskell, 2002; Saxenian, 1994). Concepts such as 'knowledge spillovers' (Audretsch and Feldman, 1996) and 'untraded

interdependencies' (Storper, 1995) are now familiar and used to describe how CL allows firms to innovate and respond flexibly and competitively in what Saxenian (1994) described as a 'protean' way. However, such ideas have also been subject to extensive critical appraisal (e.g. Martin and Sunley, 2003) not least as a result of the intervention of Markusen (1999). She argued that these 'regional studies' are often pervaded by 'fuzzy concepts' - "an entity, phenomenon or process which...cannot reliably be identified or applied by different readers or scholars" (page 870). In relation to the subject of this paper this manifests itself in the form of 'thin' descriptions of the processes that enable $\mathrm{CL}$ and treatments of 'regional learning' as a black box (Benner, 2003). Extant literatures also often fail to explore the nature of the knowledge produced through $C L$ and its affects on the competitiveness of firms in a cluster (Pinch et al, 2003). The idea of an institutional thickness (Amin and Thrift, 1995) that underlies regional economies seems equally under-specified despite frequently being cited as an important influence on the type of inter-firm relations involved in regionally-based CL (Saxenian, 1994). 
Progress has been made by some to rectify these issues (e.g. Amin, 1999; Rantisi, 2002) and this paper aims to shed further light on the CL process by focussing on the role of professional associations (PAs) as an architecture for CL. Benner (2003) has previously pointed to the value of PAs as 'regional' communities of practice (COPs) and documented how regular formal meetings and electronic listerv's allow individuals to develop "critical network[s] of relationships to help people sort through information and develop the new knowledge required to be successful in their work" (page 1821). However it is argued here that this perspective can be developed much further to explore how CL occurs, the type of knowledge that is produced and to understand how this knowledge aids the performance of firms. Through an analysis of CL in clusters of advertising and law professional service firms in London and New York this paper therefore makes three significant contributions to extant understanding.

First, through rich empirical material focussing on the PAs serving advertisers and lawyers in London and New York existing understanding of the way PAs facilitate $\mathrm{CL}$ is deepened. Building on extant theories of learning in COPs (Brown and Duguid, 2000; Lave and Wenger, 1991; Wenger, 1998; 2000; Wenger et al, 2000) it is shown how PAs seed COPs and how the subsequent 'social engagement' allows CL. This develops our understanding of how PAs act as an architecture of CL. The paper then secondly develops our understanding of why the knowledge produced through $\mathrm{CL}$ is valuable for innovation. Drawing on Marshall's (1890) theory of variation it is shown how CL allows innovative strategies to be developed in relation to shared challenges based on understanding gained from discussions of the experiences and actions of local rival firms. Finally, thirdly, the paper critically evaluates and attempts to further specify one of the affects of an 'institutional thickness' on CL. In particular it argues that one of the socio-cultural norms and values promoted by a strong 'institutional thickness' encourages the open and honest sharing of ideas and insights that allows $C L$ in order to promote the competitiveness of the cluster. This is illustrated in relation to differences in 
the success of CL in the clusters studied and variations in the strength of each clusters' institutional thickness.

The rest of the paper therefore proceeds as follows. Sections two and three begin to develop a theoretical framework through which the CL facilitated by PAs can be analysed before section four reviews extant studies of the advertising and law PSF clusters in London and New York. Sections five to seven then use original empirical material to explore how COPs are seeded by PAs, how CL occurs, how innovation is driven by the knowledge produced through $\mathrm{CL}$ and how an 'institutional thickness' affects the success of this process. Section eight provides some conclusions that evaluate the significance of these findings.

\section{2) Innovation and regional spaces}

Both academics and governments (e.g. Leadbeater, 1999; DTI, 1998) acknowledge that the competitiveness of firms comes from their ability to compete in a 'global knowledge economy' through the production and delivery of innovative services and products. One dimension of strategies to produce and exploit the knowledge upon which innovation is based is through intra-organisational knowledge management, something that increasingly has global dimensions (Amin and Cohendet, 2004). A complementary approach is the exploitation of inter-firm linkages through co-operative or collaborative relations with suppliers, customers or competitors. 'Regional' spaces have been suggested to be particularly effective at nurturing such interdependencies (Saxenian, 1994; Storper, 1995). As Tallman et al (2004) argue in relation to such learning, "regional clusters indeed do possess certain competencies that provide competitive advantage to their constituent firms as a group...Part of a regional cluster's advantage in its industry is tied to...knowledge that has originated within the cluster and remains there" (page, 268).

The value of inter-firm relations in terms of the production of innovative knowledge exists because of the incremental nature of learning and innovation. It is 
recognised in extant literatures that knowledge does not act as a static resource and that rather than degrading (as a resource does) knowledge improves with use (Brown and Duguid, 1999). Underlying the learning logic in 'regional' literatures is, as Antonelli (2000, page 537) puts it, “...growing evidence... of the collective character of technological knowledge. Technological knowledge is collective when and if it is the result of a process that combines pieces of information and knowledge that are owned by a variety of parties and cannot be traded as such".

Regional economies are potentially valuable then because of the benefits accrued from the collaborative application and development of knowledge between individual working for several local firms specialising in related commercial areas. This potentially allows innovation when the collective knowledge is applied in an appropriate way. Below further exploration of the role of PAs in the CL process is provided and the way their role in fostering interaction between individuals working for different firms can be theorised through the lens of extant work on COPs explored.

\section{3) Theorising collective learning through professional associations}

PAs are not a new phenomenon and have been an integral part of the business world for centuries. As Greenwood et al (2001) note, traditionally the role of PAs has been to lobby governments and negotiate a way between the contrasting demands of business and regulators. However, in addition they also note that PAs increasingly provide an essential forum for "the formulation and reproduction of shared meanings and understandings" (Greenwood et al, 2001, page 61). Benner (2003) noted a similar role for PAs and suggested they could be theorised as COPs because of the collective knowledge production they allow. However, instead of reciting Benner's argument this paper considers in more detail why the $\mathrm{CL}$ facilitated by PAs can be theorised as the type of social engagement described in extant COPs literatures.

Wenger et al (2002, page 4) define COPs as "groups of people who share a concern, set of problems or a passion about a topic, and who deepen their knowledge and expertise in this area by interacting on an ongoing basis". The existence of a 
'shared enterprise and engagement' is said to allow members of COPs to understand one-another's ideas and exchange experiences so as to focus "attention in a particular way and enabl[e] new kinds of understanding" (Wenger, 1998, page 60). This new understanding exists in the form of a collectively developed comprehension of the problems all members of the community face (and their potential solutions). Brown and Duguid (2000, page 106) therefore describe the knowledge production as a collective endeavour, "where one person's knowledge ends and another's begins is not always clear... neither has a decisive 'piece' of knowledge... It was a collective process that created an indivisible product". However, as Lave and Wenger (1991) point out, individuals only benefit from the learning facilitated by COPs when they can engage in 'legitimate peripheral participation'. They must "move towards full participation in the sociocultural practices of a community" (page 29). This occurs when, after starting out as peripheral members, individuals gradually move towards becoming legitimate peripheral members by proving their expertise in the COPs field of interest.

The process of establishing such communities and members achieving legitimate peripheral participation was initially seen (e.g. Lave and Wenger, 1991; Wenger, 1998) as being organic in nature. However more recently (Wenger, 2000; Wenger et al, 2000) recognition has grown that the cultivation of COPs is a valuable way to promote learning. This does not mean social engagement, the negotiation of a shared identity and the gradual integration of new members leading to their legitimate peripheral participation can be stage-managed. Rather, as Wenger et al (2000, page 12-13) describe using the analogy of cultivation, it means "a plant does its own growing...You cannot pull the stem, leaves, or petals to make a plant grow faster or taller. However, you can do much to encourage healthy plants: till the soil, ensure they have enough nutrients, supply water...Similarly, some communities of practice grow spontaneously while others may require careful seeding". It is increasingly suggested then that the knowledge production occurring through COPs might in some scenarios need initial 
encouragement through the establishment or seeding of communities which then grow of their own accord.

Based on the examination of original empirical material outlining the way $\mathrm{CL}$ occurs through the PAs serving advertises and lawyers in London and New York it is argued in this paper that PAs can sow the seeds for 'urban' COPs that allow CL. However, it is also shown that the drive to legitimate peripheral participation for any member remains an organic process negotiated with and determined by the existence of an identity matching that of other community members. In effect PAs are shown to provide a catalyst for the emergence of COPs rather than being the community as Benner (2003) suggests. Below a number of additional issues are highlighted that also need to be considered when exploring the role of PAs for CL.

\section{Competitive advantage from collective learning}

Having proposed a way to theorise the nature of the CL mediated through PAs it is also important to explore the value of $\mathrm{CL}$ to those involved. According to Pinch et al (2003) competitive advantage is gained from CL because of how it produces what they term 'architectural knowledge'. This is knowledge about "the organization of an entire system and the structures and routines for organizing" (page 380). Camagni (2002) and Kitson et al (2004) similarly argue that regional CL allows firms to develop absolute advantage in their industry from the superior technological and innovative knowledge relevant to all members of a cluster that $C L$ produces.

Such work is part of a raft of recent publications (e.g. Crevoisier, 2004; Maskell, 2001; Pinch et al, 2003) seeking to understand how CL enables firms or regions to become competitive. The principal theoretical insight connecting all of these studies is that $\mathrm{CL}$ taking place in successful clusters of firms "generates resources (e.g. knowhow, competencies and capital)...that are necessary for innovation" (Crevoisier, 2004, page 371). Stripping down these theories reveals that CL occurs when individuals with shared interests, experiences and knowledge are 'networked' and interact. In effect 
they suggest that the meeting of heterogeneous yet similarly focussed minds (as occurs in COPs) allows individuals to learn from one-another in an incremental way, something that makes firms competitive. The theory of variation further explains the value of such collectively produced knowledge.

Originally proposed by Marshall (1890), the theory of variation highlights how when firms cluster together a variety of responses to market demands will exist in one region. This allows firms to witness a variety of strategies and select, adapt and evolve those they believe are most suitable. Rantisi (2002) uses this idea to show how members of New York's fashion cluster learn by watching the responses of local competitors to fashion trends and then adapting and mutating the strategies. This helps make firms competitive as all members of the cluster learn from and improve on oneanother's attempts at dealing with shared challenges. However, this is not about replicating strategies. The resources and firm-specific beliefs and perceptions that exist in each organisation affect how the actions of others are interpreted and adapted. So Pinch et al (2003) suggest that although everyone in a cluster shares common architectural knowledge firm-specific 'component knowledge' influences decision making and the way competitors strategies are adapted and evolved. As Crevoisier (2004, page 374 ) also highlights, knowledge production by $C L$ is insufficient to make a region competitive unless there is "a capacity...shared by a number of actors...to go through the necessary learning process, and to implement the new competencies thus developed in an effective way". The capacity to do this comes from having firms with their own specific capabilities they can draw upon to adapt and enhance the strategies employed by others.

The in-depth empirical material interrogated below fleshes out these theoretical frameworks and considers how CL mediated through PAs might be beneficial. In particular it provides a valuable exploration of how variation is enabled through the interactions and exchanges of ideas, experiences and strategies facilitated by the COPs seeded by PAs. 


\section{Institutional thickness and economic practice}

The importance of the institutional 'assets' or 'thickness' of a region have also been widely shown to be influential on the way economic practices, including $C L$, are played out (Amin, 1999; Amin and Thrift, 1995; Barnes, 1999) with the concept of Institutional thickness pertaining to a variety of "local social and cultural and institutional arrangements" (Amin, 1999, page 369) ${ }^{1}$. Whilst including the provision by local actors of "training and education and access to producer services such as market intelligence [as well as] business innovation and finance" it is also noted that the socio-cultural dimensions of institutional thickness "encourag[e] dialogue and learning based on shared knowledge and information exchange (Amin, 1999, page 370-371).

Consequently, as Bathelt (2005, page 206) notes, "Norms, accepted rules, habits, conventions and other institutional arrangements are of central importance to enable interfirm communication and collaboration". They help overcome inter-firm rivalries and lead to co-operative learning relationships. However the impact of the presence (or absence) of an institutional thickness has lacked empirical exploration in many studies of CL. This is particularly troublesome because, as Barnes (1999, page 14-15) notes, it is necessary to recognise that "institutions are not all cut from the same template, but are actively constructed in certain types of place and spaces, and therefore are quire different from one-another". It means "different [institutional] norms produce different types of economic cultures" (Barnes, 1999, 16). The empirical material is therefore also used to demonstrate the affect of an institutional thickness on the COPs that allow CL and to consider how the 'embedded networks' and 'social and cultural arrangements' influence how CL is played out differently in each cluster studied. Below further context for the paper is provided through a brief discussion of extant

\footnotetext{
${ }^{1}$ Of course, as Amin (2001) reminds us, institutional assets also exist at the global scale and are not uniquely local.
} 
research of the clusters of advertising and law professional service firms in London and New York.

\section{4) Collective learning and the advertising clusters of London and New York}

Professional service firms are increasingly recognised as key 'lubricators' of the knowledge economy as the services they offer (in the form of advice) provide knowledge as an input in to clients' businesses (Morris and Empson, 1998). However, only the most innovative services allow clients to carry out their business plans as desired. For example, advertisers constantly strive to develop new and quirky strategies to tempt consumers into buying a product (Lash and Urry, 1994). Meanwhile corporate lawyers attempt to 'mould' the law around a clients business needs in order to circumvent commercially damaging legislation (Flood, 1997). These types of innovative service require high levels of expertise and knowledge of advertising or legal practices and awareness of the latest dynamics of the marketplace served. Any advantage that can be gained in the form of enhanced knowledge from $\mathrm{CL}$ is therefore potentially of great value to such firms.

It has been widely acknowledged (e.g. Sassen, 2000) that urban clustered geographies of professional service firms continue to be important, even for global organisations. Consequently London and New York are cities disproportionately important in the global economic activities of a number of firms. London is well recognised as a global centre of advertising expertise (Daniels, 1995) with Soho being the heart of a cluster of agencies. Grabher (2001) has previously noted that this 'ad village' is a vital source of learning for advertisers working in London and quotes one of his interviewees as saying "it's almost like an ideas village... like a university, without the academic side to it... people want to work here because they know they're gonna be rubbing shoulder with top directors" (quoted in Grabher, 2001, page 368). 'Rubbing shoulders' means talking to fellow advertisers, listening to their ideas and as a result learning (see also Nachum and Keeble, 2000). New York is similarly important. Leslie 
$(1995 ; 1997)$ describes how advertising agencies traditionally clustered around the thoroughfare of Madison Avenue in New York with the type of 'networking' and CL described above occurring. Meanwhile, global legal professional service firms deliver their services through offices in world cities such as London and New York (Beaverstock et al, 1999). They advise almost exclusively on corporate law (e.g. mergers and acquisitions and finance-related law) and are seen as the leading experts in the World on such matters. Surprisingly little has been written however about the activities of these firms in terms of the importance of their clustered urban geographies. Warf (2001) suggests that law firms in London have formed a 'clubby environment' that must be penetrated in order to succeed because of the knowledge membership provides access to whilst The Corporation of London (2003) highlights the potential value of CL in the London legal cluster. However, to the author's knowledge, no detailed studies exist of the CL process itself in these clusters, something this paper will begin to rectify.

The rest of this paper therefore uses the theoretical framework outlined above to look at the role of PAs in facilitating CL in London and New York's advertising and law clusters. Of course, talk of 'world cities' and TNC's reminds us that the clusters of advertising and law firms in London and New York are also highly interconnected 'nodes' in global networks (Amin and Thrift, 1992; Beaverstock et al, 1999). The literatures reviewed above (and in particular Grabher, 2001; Nachum and Keeble, 2000) have shown how knowledge is produced both in the clusters that exit in London, New York and other cities in the global economy and also between the offices of global professional service firms as knowledge circulates around firms' global office networks . However, space prohibits the integration of findings into the equally important global dimensions to knowledge production (that also formed part of the research's focus). This means that the importance of regionally focussed CL should be seen as only one of the dimensions to the multi-scalar architectures of knowledge in global advertising and legal professional service firms (Amin and Cohendet, 2004). 
The analysis of $C L$ provided in the paper is based on 58 semi-structured interviews completed with advertisers and lawyers working in London (22 of from each industry) and 14 advertisers and lawyers in New York (seven from each industry). Interviewees worked for large (normally global) advertising agencies. An acceptance rate of $25 \%$ was achieved with interviewees ranging from senior management to trainees recruited in the past three years. The interview schedule used sought detail on the role of PAs, how interviewees engaged with such bodies and what and how they learned from their engagement in the activities of PAs. Interviews were all recorded with the permission of interviewees and transcribed afterwards. Transcripts were coded using the logic of grounded theory (Glaser and Strauss, 1967) and key ideas, themes and processes highlighted. Illustrative quotes were then extracted from the transcripts. The identity of interviewees is not revealed in order to maintain their anonymity.

\section{5) The role of professional associations in seeding communities of practice}

Table 1 details the six main PAs for advertisers and lawyers in London and New York. The Institute of Practitioners in Advertising (IPA) strives to ensure members maintain "the highest possible standards of professional practice" (IPA, 2004) whilst the mission of the American Association of Advertising Agencies (4A's) is to "counsel members on operations and management", something that is designed to help advertisers "achieve desirable social and civic goals" (AAAA, 2004). In this sense then rather than focussing upon promoting $C L$ the aim of both bodies is to set and maintain standards within the advertising industry. The training programs the IPA and 4A's operate are integral to achieving this goal. The City of London Law Society (CLLC) and the Association of the Bar of the City of New York (ABCNY) have similar aims. For example, one of the ABCNY's primary aims is to represent lawyers and ensure they "maintain... high ethical legal standards for the legal profession (ABCNY, 2004).

[Insert table 1 here] 
For both advertisers and lawyers then these bodies are not explicitly designed to promote CL or the formation of 'urban' COPs. Indeed, whilst their aims inevitably lead to inorganic and institutionalised communities in the form of committees and forums that set standards, define training guidelines and lobby in support of the profession, all interviewees argued such 'communities' provide relatively little opportunity for $C L$ in relation to issues affecting the competitiveness of firms. Whilst formal committees and forums produce valuable reports outlining professional guidelines and standards that can used by firms to implement forms of best practice, interviewees suggested the greatest boon for $\mathrm{CL}$ and learning that informs innovation comes from the emergence of more informal communities. Those who attended events at PAs (21 out of 29 advertisers interviewed and 20 out of 29 lawyers) described how informal 'urban' COPs emerge and interact before and after the formal events organised by PAs. At these times advertisers and lawyers break off into smaller communities where those with shared 'identities' (for example because of having the same job role at an advertising agency or the same practice speciality in a law firm) engage in conversations that allow $\mathrm{CL}$ about issues facing all firms in the cluster. Below this catalytic affect on the emergence of informal COPs is described in more detail.

During the informal moments of formal events at PAs advertisers and lawyers working at different firms within London or New York seek out, in the crowded rooms used for pre and post event drinks, coffee breaks and lunch adjournments, those with shared interests and lines of work. This sometimes revolves around one or several of the 'gurus' of the industry as people flock to discuss topical issues with them and listen to his/her opinion. On other occasions it is simply centred on several individuals who have discovered a mutual interest through earlier discussion in the formal committee meetings, through seeing one-another's past work or, for lawyers, through past encounters as opposing counsel in a transaction. Over time as individuals attend several meetings (which occur on a frequency varying from weekly [4A's] to quarterly [Networking for Know-how]) participants begin to gel together to form a community. 
Representative comments by interviewees about this aspect of PAs role in seeding the COPs that allow CL were as follows:

"So any body that has the ability to bring people from the industry together for one cause is useful because it allows you to meet and become part of groups of people who do the same thing and share issues on an equal footing" (A13).

"Its formal that's become informal in that the actual committee meetings and other things aren't always that valuable. There are lots of little break off liaison groups within it, people who have got to know each other so when we're having discussions we do it between half a dozen of us, rather than the whole hundred odd" (L8).

Such comments highlight the value of PAs for seeding the development of COPs that allow CL. The formal activities of the PAs provide a way to bring advertisers and lawyers with similar interests together. COPs then emerge and, as is described below, grow of their own accord.

Individuals join and gradually become legitimate peripheral participants in these communities because of their shared 'identity'. 'Membership' of the COPs is based solely on a shared interest in certain issues and practices (although see below on the power relations in this process). The communities grow as individuals find common ground based on the generic challenges faced by all specialising in one area of advertising (e.g. accounting planning, management or creative production) or law (e.g. project financing, hostile take-overs). This allows debate, discussion and the sharing of ideas and experiences all members can relate to. So for example, in the Networking for Know-how (NKH) PA interviewees noted how an informal COP existed made up of professional support lawyers working for global law firms. All members of this community had a shared interest in issues facing such large organisations (e.g. how to get large institutional clients to pay their bills on time). The relationships that form around such interests then begin to bind the community and ensure those involved become legitimate peripheral participants once, over a period of time and after several 
meetings of the PA elapse, they have established their identity within the community. Each member moves towards legitimate peripheral participation as they display their existing knowledge of the community's area of expertise.

The role of the PAs in bringing individuals with 'shared practice' together and then seeding the COPs that emerge is therefore critical. It is not uncommon for over one hundred individuals from tens of different firms to be present at the formal presentations and training events that help seed the COPs described above. This means the breadth of experience and existing knowledge of those involved in the COPs is high, offering a range of perspectives that can be learned from, filtered and applied by each individual involved. This maximises the benefit gained through $\mathrm{CL}$. As one interviewee summarised the benefits of PAs for seeding such communities:

"Getting people to be friends with each other is a really good idea...So if you're a media person you need to go off on a media circle course. If you're a planner you need to get off to some account planning group thing. I do think its important and not necessarily because of what the course provides but because of the community it helps get you into and make you a part of and how you learn from the similar experiences you all have in that community" (A3)

The fact that those who did not attend events at PAs were more junior advertisers or lawyers who felt unable to contribute to discussions because of their relative immaturity further highlights the importance of members of the COPs becoming legitimate peripheral participants. Junior professionals who did not attend events at PAs effectively argued that they were unable to move towards legitimate peripheral participation in either the informal COPs or the formal committee structures. Their junior status and limited experience meant they lacked sufficient knowledge of the advertising or law field they worked within, thus preventing them from developing an identity that fitted with that of the other, generally more senior and more knowledgeable, community members. This point is returned to in the next section of the paper which moves beyond 
descriptions of how the communities emerge and function to analyse the nature of the know-how produced through CL and how it helps drive innovation.

\section{6) Collective learning driving success?}

The empirical data from this research suggests that those achieving legitimate peripheral participation in the COPs benefit from CL that produces knowledge of the challenges and changes all advertisers or lawyers working in the COPs specialist area face and need to successfully overcome to provide competitive and innovative services to clients ${ }^{2}$. This is what Pinch et al (2003) call 'architectural knowledge', knowledge that can be built upon to develop firm-specific responses to common industry challenges. Below specific examples of the type of knowledge produced through the COPs seeded by PAs are provided.

\section{Collective learning informing advertisers' responses to reflexive consumers and marketplaces}

For advertisers the reactions of reflexive consumers that change depending on recent world events make developing effective advertising incredibly challenging (Lash and Urry, 1994). This means constantly developing new knowledge of how to target diverse consumer groups. CL firstly provides valuable insights into how to address such challenges through advertising strategies. At the time of completing interviews discussion of consumer responses to the September $11^{\text {th }}$ terrorist attacks continued to be important as well as discussions of the potential for new regulation in the UK of 'Junk food'- products targeted at children containing high levels of sugar, fat and salt. All advertisers were dealing with the affects of such issues on consumer responses and the impacts of regulatory changes on advertising 'boundaries'. It was therefore beneficial to

\footnotetext{
${ }^{2}$ Members of COPS also benefited from knowledge of job vacancies and general gossip in relation to what other individuals in the industry were doing and which firms they were moving between. However this does not help make them or their firms more competitive.
} 
exchange insights into how to deal with these challenges and changes in the advertising market place as future strategies could be influenced by the different approaches and experiences of the range of advertisers present at the PA. The second way CL produces valuable knowledge is through the exchange of opinions about recent advertising campaigns. Sharing insights and interpretations of the strategy behind a campaign, techniques used and the affect on the consumer helps inform future thinking when developing innovative and effective strategies for similar brands or market segments. In effect it allows individuals to learn from others mistakes and experiences. As one advertiser put it:

"Yeah there is quite a lot of that [discussing adverts]. 'Oh my god don't you love the new campaign for whoever' or 'have you seen that load of old shite so and so have done', that happens a lot. And I suppose it's quite useful, if you get into one of those conversations you tend to deconstruct everything and go 'well the campaign before had this message targeting these people and the campaign now.... it's important because the more of those conversations you have the better you get at deciding what will work" (A8).

\section{Collective learning informing lawyers' response to legislative change}

For lawyers conversations in the COPs seeded by PAs are normally about recent changes in legislation or landmark cases and the implications for the way everyone approaches certain types of transactions. The legal field is constantly changing with the type of corporate law dealt with in London and New York being more dynamic than civil law. Consequently being able to share insights and learn from oneanother in relation to such changes is seen as vital. One of the issues commonly discussed by lawyers in London at the time of this research was the affect of amendments contained within the Department for Trade an Industry's 'Takeover Directive' and how they could be understood and applied in transactions. For lawyers in New York developing understanding of the evolving nature of 'Asset backed securities' through CL proved highly valuable. Again, the benefit of such conversations lies in how they allow the different experiences and ideas of community members to be explored 
and learned from in relation to these topics and shared challenges. This then means the demands of clients for innovative structures to allow transactions to be completed in commercially beneficial ways can be met. Any corporate law firm unable to do this would soon lose clients. As one lawyer noted about how insights gained from CL allow the development of such innovative client services:

“...there are always going to be issues which are arising that all of us are grappling with and trying to make sense of. A good example of that was when the new Financial services and Markets Act came into effect. That completely replaced some legislation we'd had since 1986 which everybody was very familiar with and it was key legislation for any listed company...So actually then that was a good example of people talking to each other across different firms... and say[ing] 'how do we think this particular section of the act is actually going to work, what do we think these words actually mean?' What experience of this issue have you had? So it just made sense because that was something affecting all of us and we could gain valuable insights from one-another into how it may affect transaction we have to work on" (L3).

\section{Collective learning and competitiveness}

For the majority of advertisers and lawyers interviewed then there was no doubt that PAs and the CL they allow is essential. Although it is possible to innovate and develop knowledge within the firm of the type of issues discussed in COPs it is most effective to also develop a collective understanding with members of the profession working for rival firms. This creates a richer understanding than intra-firm learning alone. As one interviewee described the role and importance of such knowledge and how the insights gained from CL informs their future work:

“...as a firm we try to ensure we have people who get onto those committees and at the professional bodies... as a partner and I found it absolutely invaluable, discussing with other people and getting a different dimension and perspective of what they do and they way they do it. I'd come back and tell all my colleagues and we can base our future work on what I learned from other lawyers at the City of London Law Society." (L22). 
CL produces then knowledge upon which firms can base their responses to the latest problem or client demand. As Marshall's (1890) theory of variations suggests, listening to how other professionals and their firms approach common problems allows individuals to learn from a range of strategies, experiences and insights. It is then possible to interpret and assimilate this collective knowledge and decide how to adapt or evolve the strategies discussed based on existing (personal) understanding, firmspecific competences and insight gained from the wider global networks the professional service firms in London and New York operate. The result is variegated responses by each firm under laid by insights from the evaluation, combination and reconfiguration of the approaches and ideas of others. As two interviewees commented:

"So its quite useful to know what other people are doing to give you ideas to maybe springboard off but its not trying to copy them or do it exactly the same - clients don't want that they want us to use our expertise" (L3).

"We talk about adverts, advertising, accounts we're working on and gossip. Talking about adverts is useful because you get an opinion from someone, and opinion that is reasonably informed and probably slightly different from the ones you'll get from people who work at the same place as you. So they might go away and respond to the issue totally differently to you but at least you can use the insights you gained to influence your decisions" (A20).

It seems then that the $\mathrm{CL}$ process has a significant role in making the advertising and law clusters into what Saxenian (1994) would call a protean place: a place where firms are able to easily adapt to new market demands. Whereas others have noted the benefits of visually witnessing the strategies of rivals (e.g. Rantisi [2002] on fashion) this suggests talking is valuable for learning about, understanding and then in the future adapting and evolving competitors' strategies. 
Analysing the comments of those not involved in the activities of PAs and therefore not involved in the COPs that allow CL and the effect this has on their ability to deal with the types of issues discussed at PAs further reinforces this argument. These individuals recognised that they lost out in terms of knowledge and understanding they were not privy to and the ability this provides to build on the insights of other professionals and firms. As one interviewee put it:

“...you do miss out actually on the context of the debate, you get a better understanding of the pro's and cons, the arguments for and against particular things, so it's a shame when you don't get to be part of those groups" (L4).

All of the firms studied in the research had one or several employees who were members of the PAs listed in table 1 and were therefore never totally excluded from the benefits of $\mathrm{CL}$. However it was recognised that the more members of the PAs there were within a firm the more COPs it was possible to 'penetrate' and benefit from. The presence and exploitation of CL mediated through PAs would seem then one, amongst many, of the vital regional assets that make firms competitive. However, the results presented here suggest $C L$ is imbued with power relations that, in particular, exclude newcomers. This point is returned to in the conclusions section of the paper.

\section{7) Exploring the role of institutional thickness in collective learning}

This section of the paper considers the affect of an 'institutional thickness' on the emergence of the COPs described above and the success of CL. In particular it provides a sensitive account of how underlying socio-cultural norms 'embed' and influence the way economic practices are played out. It is essential to understand this to fully understand how the COPs seeded by PAs allow CL.

The formal events at PAs are structured to bring individuals from different (rival) firms together. Consequently the COPs that emerge are made up of advertisers and 
lawyers from a range of firms who talk and learn from one-another and benefit in the ways described above. The comments of two interviewees reinforce this point:

“...at the IPA people might chat about what should we be doing about this, should we follow the industry view which says do this? What is the policy adopted by other agencies?' And you can learn from advertisers from other firms and take the ideas away with you back to your agency" (A1).

"It's a very small market place with probably 15 or less trying to be that type of [large corporate law] firm and we all know each other because we deal with each other all of the time. We all face similar challenges need to find solutions to common problems so it makes sense to be open and share things" (L9).

It is important to note however that the conversations described in these quotes are reliant upon a high level of openness between professionals in what are extremely competitive market places. It seems somewhat paradoxical for industries where both the firms compete fierously and individual 'star players' are well-known for their rivalry in terms of the development of creative ideas in advertising (Grabher, 2002) and feeearning in law (Hanlon, 1997) to have practices that involve the sharing of ideas and insights. However, interviewees in three of the four clusters studied argued that even 'star players' acknowledge the importance of a 'collective endeavour' when it comes to developing understanding of new and troublesome issues that plague all in the industry ${ }^{3}$. It is argued here that this diminishment of inter-firm rivalries is reliant on the existence of an institutional thickness affecting the norms, beliefs and behaviours of individuals. The nature of CL in London's advertising clusters illustrates the affect of the presence of such an institutional thickness on the COPs seeded by PAs.

In London all of the advertisers interviewed had either attended one of the various training courses both the IPA and the APG offer and/or were a member of one

\footnotetext{
${ }^{3}$ As the discussion of variation above highlights, it is how the individual filters, interprets and applies the insights gained from CL that makes them a 'star player'.
} 
of the various committees. They argued that PAs and the COPs they seed provide a critical architecture for CL in London's advertising cluster. However it was also noted that the success of this CL was reliant on the willingness of members of the informal COPs to be open and honest and share ideas and insights with fellow professionals. The following comments are representative of this idea:

“...I chair one of their working parties so that's how I network with other people and the IPA is very good because it brings people together to share issues in an open and honest forum - there's really no point in going if you're not willing to talk freely about things... So any body that has the ability to bring people from the industry together for one cause is useful if it can tap into peoples desire to contribute to the profession they are a part of" (A13).

"The advertising industry is... a pretty incestuous industry here in London and I think that a lot of people within the industry but within different companies talk to each other...definitely in advertising, people like to share with their peers what they're up to and feel it's the right thing to do when they're all in the same boat, doing similar things, having similar difficulties" (A21).

These quotes illustrate then the importance of advertisers being open and honest and willing to discuss their ideas and experiences with 'rivals'. This does not mean giving away firm-specific 'secrets' (component knowledge). Rather it means being willing to work towards a collective understanding of shared challenges (architectural knowledge). As a result the COPs most successful at encouraging $\mathrm{CL}$ are those emerging within PAs where members feel a compulsion to engage in $\mathrm{CL}$ out of loyalty to the wider professional community in the city in order to develop its competitiveness. All interviewees recognised that they were competing for business in a global marketplace and that developing the ability of, in this case advertisers in London, to serve global clients was essential for the clusters overall reputation and success. CL was one of the ways of contributing to such cluster development and sustenance. 
Such behaviour reflects a shared socio-cultural belief or institutional norm that all advertisers in London share. The learning networks are embedded in an institutional thickness that has a positive affect on the behaviour of professionals. Below the importance of such a 'thickness' is analysed further. The empirical data reveals how the 'thickness' facilitating CL varies in existence and strength in the other clusters studied. Consequently the success of $\mathrm{CL}$ also varies.

\section{Strong institutional thickness and enhanced collective learning}

The suggestion that an institutional thickness allows PAs to act as mediators of $\mathrm{CL}$ is further reinforced by analysing the $\mathrm{CL}$ process in the law clusters in London and New York. Thirteen of the 22 lawyers interviewed in London were members of the CLLS whilst four interviewees were members of the NKH group (with no interviewees being a member of both PAs). All of those not attending events at the CLLS or NKH group (five interviewees) were younger lawyers and unsure about the PAs suitability for young professionals because of the reasons described earlier in the paper.

In both PAs and the COPs they seed it was again the discussion between lawyers from different firms that was seen as valuable. The willingness of individuals to participate in events and be open and frank with their ideas and experiences was therefore essential and ensured the type of valuable conversations previously described took place. As one lawyer described it:

“When I was first contacted to see if I'd like to join, my first reaction was well, I don't think I really need this organization [the NKH PA]...But actually from the very first meeting | realised that my opinion was totally wrong and l'd a huge amount to learn from other people at other firms and I also had things to contribute that might helps others as well. And its unbelievable sometimes how much people are willing to share with you, and that what makes these meetings so valuable and worth attending" (L3).

The PAs in London provide then vital opportunities to share ideas and insights through open and honest conversations. The interviewees suggested this was something most 
lawyers saw as normal practice whilst always being slightly guarded so as to retain some degree of competitive advantage. The rational for being so open lay, as it did for advertisers, in part in the advantages to be gained from London being seen as a global centre for innovative corporate as well as in the benefits it bought in terms of the success of individuals and firms. Being part of a cluster of firms that were all innovative and dealing with the same cutting edge issues was therefore seen as beneficial when CL occurred. This reflects Porter's (1998) idea that clusters promote innovation because of the synergistic affect of competing companies operating in proximity to oneanother. It suggests however that the benefits come less from competition and more from, where occurring, the advantages of CL.

For lawyers in New York the ABCNY is the principal professional association and is important for CL in much the same way as the CLLS. Five of the seven lawyers interviewed in New York attended events of the ABCNY with four sitting of specific committees. The two lawyers who did not attend were again more junior. Those who attended the events again noted that a collegiality exists between professionals in the city. However, such suggestions were made in an even stronger manner than by lawyers in London. Lawyers in New York argued that a shared socio-cultural value of openness that promotes the sharing of learnings amongst fellow lawyers in the city results in an even greater desire to be involved in PAs and the COPs they seed than in other cities. As two lawyers described it:

"...attending [events at the ABCNY] is a major source of knowledge [and] is much more developed than anything else in the UK...Lawyers at these forums are very very open, there's a huge amount of generosity and I'm a frequent attendant and learn a lot...I also think that sharing knowledge is advancing the profession and one of the obligations of being a lawyer. A people are very generous about it, very open about sharing knowledge" (L24).

"On a regular basis I go to the American Bar Association, get together with lawyers from other firms where we bat things around...its wonderful. I mean obviously you have to do 
it in such a way that doesn't disclose client confidences and that sort of thing but when you get together with other professionals in your particular area of expertise and they're pretty open about the nature of the problems they encounter and that can be extremely important" (L25)

It is hard to be certain that such descriptions confirm the existence of a 'thicker thickness' in the New York law cluster than in London or that the resultant CL is more effective. Lawyers may have been engaging in an exercise of self-promotion, depicting themselves as 'good professionals'. However, the above comments are undoubtedly qualitatively different to those made by lawyers in London. Indeed one lawyer in New York when asked about whether they felt they should share knowledge with lawyers at rival firms commented that "[y]ou don't speak to rival firms you speak to lawyers and they are from other firms and you don't worry about it" (L28). This would suggest that the law profession in New York does have a stronger feeling of mutual allegiance than its counterpart in London and that this could be conceptualised as a stronger institutional thickness, as a norm and culture that binds members of the cluster more tightly together and results in more open and honest sharing of ideas and experiences. This would further suggest a strong institutional thickness is vital for promoting the $\mathrm{CL}$ that helps sustain a clusters competitiveness.

The fact that both the CLLS and ABCNY were established as a result of desire within the existing professional clusters for a body to help exploit the collective professionalism that existed and use it for the benefit of all lawyers and their clients (ABCNY, 2004; CLLS, 2004) further reinforces the idea that an 'institutional thickness' underlies and embeds the success of the PAs and the COPs they seed. It suggests that successful PA's act as a structure or architecture that can exploit existing institutional thickness as well as reinforce its existence. The COPs seeded by PAs tap into this institutional asset and develop valuable collective knowledge. The argument that an institutional thickness helps encourage $C L$ is further galvanised by analysing the affect of a 'weak' thickness on CL in New York's advertising cluster. 


\section{Weak institutional thickness and restricted collective learning}

In New York there is only one key PA for advertisers (see table 1) in the form of the 4A's. Until recently there was also a New York version of the APG but this recently closed. Participation by advertisers in the activities of PAs operating in New York was however somewhat limited compared to in London. All of the advertisers interviewed were aware of the existence of the 4A's but only two had been involved in any of their activities. Those advertisers who had taken part in events at the 4A's suggested they were poorly attended and were negative about their benefits. Of particular relevance here is the fact that the COPs described above consequently fail to emerge and where they do they are of little benefit as members are coy when discussing their ideas and experiences. As one advertiser in New York noted:

"I think the more productive exchanges are the interpersonal ones because you end up with a network of people that do the same thing and who are willing to take the time and be honest with you whereas when you go to meetings at the four A's or wherever people really don't want to share things with you" (A29).

This quote illustrates how the PAs in New York are less effective at allowing CL to occur because of a reduced willingness of members to share insights, experiences and ideas with other community members. It is unclear exactly why advertisers in New York take such an approach and are less willing to participate in events at PAs than their counterparts in London. However, those with experience elsewhere believed the resultant lack of CL had a negative affect. One advertiser lamented the fact that their colleagues were not more like the people they had worked with in London during an overseas secondment and suggested:

"But from working in London and working here [in New York], the difference there was that all the creatives from all the different places all ended up together at the IPA just talking a lot more freely amongst themselves. And the whole industry benefits from that. I wish we had that a bit more here in the States" (A28). 
The effect of the reduced collegiality, which is argued here to show a weaker 'institutional thickness' is then a reduced level of CL in the New York advertising cluster. It suggests that the cultural norm associated with engagement in the activities of PAs has not grown in the same way as it has in the other three clusters. Although it is difficult to quantify this affect the comments below show how advertisers in New York felt that an 'insular' and constrained feeling existed as they had few opportunities to listen to the ideas and opinions of advertisers outside of the firm they worked for. As two interviewees noted:

"Every agency is its own little fiefdom and it's useful to talk to someone on the inside who can tell me what's going on. And you get important insights from that which are missing if you never talk to anyone apart from someone in the next office. But we're not very good at that, it only happens if you've got a friend working in another agency" (A23).

"The problem I suppose we have is that we don't get to ask each other and ask if they've done something and get an inside track on things that being able to talk to people from other agencies really comes in handy. And I valued that when I was in London" (A28).

This suggests then that advertisers in New York feel they lose out on the benefits CL brings in terms of innovation. In particular as the interviewees quoted above noted, it means that although CL does still occur interpersonal friendships are the only source of insight. These take much longer to nurture and span fewer organisations than conversations in COPs. They do not therefore have the same value as the exponential learning that occurs in the 'urban' COPs described above.

The analysis of the empirical data from this research is suggested here to highlight the role and importance of an 'institutional thickness' in facilitating CL and also the implications of variations in its strength between clusters. It seems to suggest that a lack or weakness of such a thickness prohibits the successful enactment of the activities 
of both the PAs and also the COPs that form. This potentially constrains the abilities of firms to be innovative and protean in their response to market changes.

\section{8) Discussion and conclusions}

This paper builds on existing understanding of the CL process in regional economies and combines both a theoretical and empirical analysis of the role of PAs in seeding COPs to critically analyse how COPs emerge, how knowledge is produced, the factors that facilitate the $\mathrm{CL}$ process and why $\mathrm{CL}$ is important in making firms in a cluster competitive. In doing this it makes three distinct contributions to existing understanding of this phenomenon.

First it further builds on existing awareness of the importance of PAs in CL (e.g. Benner, 2003) and explores how such bodies act as an architecture for the process. In doing this it suggests that such bodies can have an important seeding affect on COPs that allow $\mathrm{CL}$ and therefore act as an architecture to tap into the socio-cultural institutional assets. This both complicates and reconfigures explanations developed in

previous work (Benner, 2003; Greenwood et al, 2001) and highlights how the COPs that allow CL form, how members achieve legitimate peripheral participation and why this leads to $C L$ that helps makes firms innovative and competitive. In particular the shared professional engagement of all members of the PA has been shown to allow understanding of shared problems to develop, something that both gels professionals in the communities and also ensures the $C L$ is of value to all involved. This begins to address some of the critical questions raised about the CL process (e.g. Markusen, 1999) and provides an 'unfuzzy' conceptualisation that opens the 'black box' of CL and shows how knowledge is produced and 'spills over'.

Secondly the paper provides insight into the role and importance of the knowledge produced by $C L$ in making cluster-member firms successful. It is widely argued that CL drives the success of firms (e.g. Saxenian, 1994) and the results presented here provide further insights in to the nature of the knowledge produced and 
its importance. It illustrates how the output of CL through 'urban' COPs (knowledge relevant to shared challenges that can inform future action) enables the advertising and law professional service firms clustered in London and the law professional service firms in New York to address key industry challenges in an innovative and effective way. Drawing on Marshall's (1890) theory of variation it showed how decision-making is influenced by the adaptation and evolution of insights gained from discussion of the experiences, strategies and ideas of other firms in the COPs seeded by PAs. This drives competitiveness because of the ability it gives firms to be 'protean' in their responses to the dynamic marketplaces they serve (Saxenian, 1994).

Thirdly, the paper begins to flesh out one affect of the ambiguous and underspecified concept of institutional thickness. It first determined the nature and importance of such a socio-cultural value for $\mathrm{CL}$. This was exemplified by the presence and absence of an institutional thickness in London and New York's advertising clusters (and the success and failure of collective learning in each). It suggests that $C L$ and the role of PAs in this process is reliant on more than simply the existence of a cluster of firms and PAs to bring professionals together. Instead it suggests $C L$ also requires an ingrained set of norms and values that promote the type of collegiality and collectivism that allows learning. Such a value is shown to be contingent however and place specific, something that most likely grows over time and needs nurturing (Amin, 1999; Barnes, 1999).

Combined, these insights highlight the need to continue to complicate and advance understanding of the practices, affects of and constraints upon $\mathrm{CL}$ in order to better understand how it might drive the competitiveness of firms in regional economies. In particular it raises five important questions that should be addressed through future research. First, the paper highlights the need to better understand the affect and dynamics of the 'institutional thickness' identified. Further examination of the precise nature, growth, decline and impact of such institutional affects is critical if we are to better theorise the socio-cultural influences on economic practices in regional 
economies. Second, although the paper has made some tentative suggestions about the affect of $C L$ on the competitiveness of firms there seems to be the need for further work that better develops 'measurement' techniques to assess the value-added of regional assets such as PAs and the CL they seed. This would involve developing better understanding of how 'protean' abilities are enhanced for those involved in CL and diminished by exclusion from the process. Third, the absence of analysis in this paper of the global dimensions to learning should also be rectified by future studies. It is clearly important to further analyse and document how $\mathrm{CL}$ is inter-weaved with global knowledge networks in order to prevent a debilitating locally fixed focus upon knowledge and learning (Amin and Cohendet, 2004). As part of this the unresolved debate about whether local 'buzz' and global 'pipelines' (Bathelt et al, 2004) differ needs further investigation. Fourth, the paper reveals important power relations involved in the $\mathrm{CL}$ process. This was in the form of the exclusion of newcomers from the informal COPs that allow CL. This suggests $C L$ is a power laden process, something that might affect the dynamics of a cluster and clearly needs further investigation. Finally, fifthly, it seems important to consider how these processes are also important for professional service firms outside of world cities. As was noted, many of the PAs studied have 'regional' branches and it would seem valuable to consider whether these branches operate in 'provincial' cities in the same way and with the same success and constraints. All of these points clearly suggest there is much work to be done as part of a future research agenda. 


\section{References}

AAAG, 2004, "The mission of the American Association of Advertising Agencies"

http://www.aaaa.org/inside/mission.pdf

ABCNY, 2004, "Constitution of the Association of the BAR of the City of New York"

http://www.abcny.org/aboutus/constitution.html

Amin A, 1999 "An institutionalist perspective on regional economic development". International Journal of Urban and Regional Research 23 365-378.

Amin A, 2001, "Moving on: institutionalism in economic geography". Environment and planning A

$331237-1241$.

Amin A, Cohendet P, 2004, Architectures of knowledge. (Oxford University Press, Oxford).

Amin A and Thrift N (1992) Neo-Marshallian nodes in global networks. International Journal of Urban and Regional Research 16571 - 587.

Amin A, Thrift N , 1995, "Globalisation, institutional thickness and the local economy". In Managing Cities Eds Healey P, Cameron S, Davoudi S, Graham S and Madani-Pour (Wiley, Chichester) pp91-108.

Antonelli C, 2000, "Collective knowledge communication and innovation: the evidence of technological districts". Regional studies 34(6) 535-547.

APG, 2004, "Mission statement". http://www.apg.org.uk/aboutus/mission

Audretsch D, Feldman MP, 1996, "R\&D spillovers and the geography of innovation". The American economic review 86 630-.

Barnes T, 1999, "Industrial geography, institutional economics and Innis". In The new industrial geography. Regions, regulation and institutions. EDS Barnes T and Gertler MS (Routledge London and New York) pp 1-22. 
Bathelt H, Malmberg Am Maskell P, 2004 "Clusters and knowledge: local buzz, global pipelines and the process of knowledge creation" Progress in Human geography 28 31-56.

Beaverstock JV, Taylor PJ, Smith RG, 1999, "The long arm of the law: London's law firms in a globalising world economy" Environment and Planning A 31 1857-1876.

Benner C, 2003, "Learning communities in a learning region: the soft infrastructure of cross-firm learning networks in Silicon Valley" Environment and Planning A 35 1809-1830.

Brown JS, Duguid P, 2000, The social life of information (Harvard business School press, Boston MA).

Camagni R , 1991, "Local milieu, uncertainty and innovation networks: towards a new dynamic theory of economic space". In Innovation networks: spatial perspectives. Ed Camagni R (London, Belhaven) pp 121-142.

CLLS, 2004, "Who we are" http://www.citysolicitors.org.uk/Who we are/default.asp?s=2\&lo=2 Daniels PW, 1995, "The internationalisation of advertising services in a changing regulatory environment" The service industries journal 15(3) 276-294.

DTI, 1998, Our competitive future building the knowledge driven economy (DTI White Paper available from www.dti.gov.uk/comp/competitive).

Flood J, 1996 "Megalawyering in the global order: the cultural, social and economic transformation of global legal practice" International journal of the legal profession 3(1/2) 169-214.

Florida R,1995, "Towards the learning region" Futures 27(5) 527-536.

Glaser B, Strauss A, 1967, The discovery of grounded theory (Aldine, Chicago).

Grabher G, 2001, "Ecologies of creativity: the village, the group and the heterarchic organisation of the British advertising industry". Environment and Planning A 33 351-374. 
Greenwood R, Suddaby R, Hinings CR, 2002, "Theorizing change: the role of professional associations in the transformation of institutionalized fields" Academy of management journal $\mathbf{4 5}$ (1) $58-80$.

Hodgson G, 1999, Economics and Utopia: Why the learning economy is not the end of history (Routledge, London).

IPA, 2004, "About the IPA" http://www.ipa.co.uk/membership/who.cfm?menulink=true Keeble et al 1999

Lash S, Urry J, 1994, Economies of signs and spaces (London, Sage)

Lave J, Wenger E, 1991, Situated learning. Legitimate peripheral participation (Cambridge University Press, Cambridge).

Kitson M, Martin R, Tyler P, 2004, "Regional competitiveness: an elusive yet key concept?" Regional studies 38(9) 991-999.

Leadbeater C, 1999 Living on thin air: the new economy (Viking, London).

Leslie DA, 1995, "Global scan: the globalization of advertising agencies concepts, and campaigns" Economic Geography 71(4) 402-426.

Leslie D, 1997, “Abandoning Madison Avenue: the relocation of advertising services in New York city" Urban geography 18(7) $568-590$.

Malmberg A, Maskell P, 2002 "The elusive concept of localization economies: towards a knowledge-based theory of spatial clustering" Environment and Planning A 34 429-449.

Markusen A, 1999, "Fuzzy concepts, scanty evidence, policy distance: the case for rigour and policy relevance in critical regional studies". Regional studies 33(9) 869-884.

Marshall A, 1890, Principles of economics (Macmillan and Co London). 
Martin R, Sunley P, 2003, “Deconstructing clusters: Chaotic concept or policy panacea?” Journal of Economic Geography 3 5-35.

Maskell P, 2001, "Towards a knowledge based theory of the industrial cluster" Industrial and Corporate Change 10(4) 921-943.

Maskell P, Malmberg A, 1999, "Localised learning and industrial competitiveness". Cambridge journal of economics 23 167-185.

Morris T, Empson L, 1998, “Organisation and Expertise: An Exploration of Knowledge Bases and the Management and Consulting Firms" Accounting, Organisations and Society 23(5/6) 609-624.

Nachum L, Keeble D, 2000, "Foreign and indigenous firms in the media cluster of central London" ESRC centre for business research working paper no. 154. Copy available from http://www.cbr.cam.ac.uk/publications/index.htm NKH, 2004, "The networking for know-how group" http://www.complinet.com/nfk/login.html.

Pinch S, Henry N, Jenkins M, Tallman, S, 2003 "From 'industrial districts' to 'knowledge clusters': a model of knowledge dissemination and competitive advantage in industrial agglomerations" Journal of economic geography 3 373-388.

Porter ME, 1998, On competition (Harvard business review book, Boston MA).

Rantisi NM, 2002, "The local innovation system as source of 'variety': openness and adaptability in New York City's garment district" Regional Studies 36(6) 587-602.

Sassen S, 2000, Cities in a world economy, $2^{\text {nd }}$ edition (London, Pine Forge Press).

Saxenian A, 1994, Regional advantage. Culture and competition in Silicon Valley and route 128 (Harvard University Press, London).

Skyrme DJ, 1999, Knowledge networking. Creating the Collaborative enterprise (ButterworthHeinmann, Oxford). 
Storper M,1995, "The resurgence of regional economies ten years later: the region as a nexus of untraded interdependencies" European Urban and Regional Studies 2(3) 191-221.

The Corporation of London, 2003, Financial service clustering and its significance for London (Corporation of London, London)

Warf B, 2001, "Global dimensions of US legal services" The Professional Geographer 53(3) 398406.

Wenger E, 1998, COP: learning meaning and identity (Cambridge University press, Cambridge) .

Wenger E, 2000, "Communities of Practice and Social Learning Systems" Organization 7(2) 225246.

Wenger E, McDermott R, Snyder WM, 2002), Cultivating communities of practice. (Harvard Business School Press, Boston Massachusetts) 
Law City of London Law Society (CLLS)

Aim: "The Society acts as the City's local Law Society and represents the professional interests of City solicitors" (CLLS, 2004).

Key activities: Establishment of committees for all key areas of law practised by City lawyers; Social events to bring lawyers together.

\section{Networking for know-how (NKH)}

Aim: "Networking for Know-how is an independent association of, and for, support lawyers working in the area of corporate law and regulation... It provides a forum for learning and discussion about matters of common professional and legal interest; exploring and promoting aspects of the work, and development of, corporate professional support lawyers; and making of contacts within the legal professional support community". Professional support lawyers are defined by the body as, "amongst other things, [the]'proxy's for a firm's transactional lawyers in keeping track of legal and other developments and in creating and managing a firm's know-how effectively" (NKH, 2004). They are in effect the knowledge managers of law firms.

Key activities: Through member meetings, lectures and technical discussions as well as social events provide professional support lawyers with knowledge to help them in their profession.

\section{The Institute of Practitioners in Advertising (IPA)}

Aim: " [To] serve, promote and anticipate the collective involvement of all members; and in particular to define, develop and help maintain the highest possible standards of professional practice within the business" (IPA, 2004).

Key activities: To provide training opportunities for advertising

executives; to organise social events for advertising professionals. The Account Planning Group (APG)

Aim: "To champion excellence in creative thinking...to encourage the sharing of best practice in innovation in planning...to encourage dialogue amongst its members..." (APG, 2004).

Key activities: Through committees and training enable creative thinking and the sharing of insights.

\section{The Association of the BAR of the City of New York (ABCNY)}

Aim: "cultivating the science of jurisprudence, promoting reforms in the law, facilitating and improving the administration of justice, elevating the standard of integrity, honour and courtesy in the legal profession, and cherishing the spirit of collegiality among the members thereof" (ABCNY, 2004)

Key activities: To provide committees covering all key areas of interest and through lectures and development activities give lawyers the skills they need to practice.

\section{The American Association of Advertising Agencies (4A's)}

Aim: "To improve the strength of the advertising agency business in the US by counselling members on operation and management" (AAAG, 2004).

Key activities: Through selective membership developing a restricted body of information and resources that will help develop a firms business.

Table 1. The key professional associations for advertisers and lawyers in London and New York. 
